\title{
DENSITY, MICROSTRUCTURE, STRENGTH AND FRACTOGRAPHY OF SPARK PLASMA AND CONVENTIONALLY SINTERED Mn STEELS
}

\author{
M. Tenerowicz-Zaba, M. Kupkova, M. Kabatova, E. Dudrova, M. Dzupon, \\ M. Sulowski
}

\begin{abstract}
The aim of the study was to investigate Spark Plasma Sintering (SPS) of 1-3\%Mn steels and compare the resultant microstructures, strengths and failure mechanisms with those of conventionally sintered materials. SPS was performed in a vacuum of $5 \mathrm{~Pa}$ at $1000^{\circ} \mathrm{C}$ for $15 \mathrm{~min}$ under a uniaxial pressure of $20 \mathrm{MPa}$. The heating rate of $100^{\circ} \mathrm{C} / \mathrm{min}$ was applied. For conventional processing, mixtures of powders were prepared in a Turbula mixer for 30 minutes. Samples were single pressed at $660 \mathrm{MPa}$, according to PN-EN ISO 2740 standard. Sintering of compacts was carried out in a laboratory tube furnace at $1120^{\circ} \mathrm{C}$ and $1250^{\circ} \mathrm{C}$ for 60 minutes in a mixture of $95 \% \mathrm{~N}_{2}-5 \% \mathrm{H}_{2}$. Heating and cooling rates were $75 \mathrm{C} / \mathrm{min}$ and $60^{\circ} \mathrm{C} / \mathrm{min}$, respectively. The density of SPS samples was higher (up to $7.37 \mathrm{~g} / \mathrm{cm}^{3}$ ) than those after conventional sintering (up to $\left.6.7 \mathrm{~g} / \mathrm{cm}^{3}\right)$. Yield strengths of SPS samples were in the range 920-1220 $M P a$, compared to the maximum of $602 \mathrm{MPa}$ for conventionally sintered $\mathrm{Fe}-3 \% \mathrm{Mn}-0.8 \% \mathrm{C}$. Transverse rupture strengths were the same for this alloy, $1234 \mathrm{MPa}$, but reached $1473 \mathrm{MPa}$ for SPS 2Mn variant. Interfaces in SPS samples were significantly less contaminated with oxides, which is the result of a more favorable microclimate and pressure acting during SPS. These preliminary results indicate that further research on the SPS of Mn steels is warranted.
\end{abstract}

Keywords: Spark Plasma Sintering (SPS), sintered steels, mechanical properties

\section{INTRODUCTION}

In conventional powder metallurgy (PM) manganese is commonly used as an alloying element. It is increasingly added to steel instead of nickel because manganese is cheaper and has no harmful influence on the environment. This element can be added to a powder mixture as ferromanganese or an electrolytic powder. The main problem with using manganese is its high affinity to oxygen and high vapour pressure at sintering temperature [1]. Spark Plasma Sintering (SPS) is quite a new method of sintering, and now it is a third generation sintering method which use pulses of electrical energy. In 1933 the first attempts at sintering using electrical impulses were carried out [2-4].

\footnotetext{
Monika Tenerowicz-Zaba, Maciej Sulowski: AGH University of Science and Technology, Faculty of Metals Engineering and Industrial Computer Science, Cracow, Poland

Miriam Kupkova, Margita Kabatova, Eva Dudrova, Miroslav Dzupon: Institute of Materials Research, Slovak Academy of Sciences, Košice, Slovakia
} 
Firstly, it was called Spark Sintering [5] and in 1950 Lenel explored this method, then in second generation (90's) it was Plasma Âctivated Sintering. The apparatus provided maximum pressure $50 \mathrm{kN}$ and DC current 800 A. Nowadays SPS machinery allows us to obtain pressure $3000 \mathrm{kN}$ and DC current 60000 A during the process [6]. SPS uses DC pulses and Joules' law to change electrical energy to internal energy. During processing the temperature between particles can be very high and causes "skin effect" and melting, intermolecular linking [7]. During SPS first microplasma discharge takes place, then Joule heat affects diffusion and bonding of particles [8]. SPS is a much faster sintering technique than conventional PM processing. Whole the SPS process can take up to $20 \mathrm{~min}$. Fast heating, and very high temperature between particles obtains higher density, without grain growth, than conventional PM processing.

The aim of paper is to present preliminary results achieved for samples prepared by SPS and compare with the results for pressed and sintered specimens.

\section{EXPERIMENTAL}

As a starting materials, iron NC 100.24 (Höganäs AB Sweden), ferromanganese Elkem II (Eramet Norway Sauda) with particle size $<40 \mu \mathrm{m}$ and graphite C-UF (Höganäs AB Sweden) were used. Powder mixtures were prepared in a Turbula mixer for 30 min. Three chemical compositions were prepared: $\mathrm{Fe}-1 \% \mathrm{Mn}-0.8 \% \mathrm{C}, \mathrm{Fe}-2 \% \mathrm{Mn}-0.8 \% \mathrm{C}, \mathrm{Fe}-$ $3 \% \mathrm{Mn}-0.8 \% \mathrm{C}$.

The SPS samples, discs with diameter $30 \mathrm{~mm}$, were prepared in the Institute of Material Research, SAS in Kosice by spark plasma sintering in the furnace HP D10-SD (FCT Systeme $\mathrm{GmbH}$, Germany) in a vacuum of $5 \mathrm{~Pa}$ at $1000^{\circ} \mathrm{C}$ for $15 \mathrm{~min}$ under a uniaxial pressure of $20 \mathrm{MPa}$ at a heating rate of $100^{\circ} \mathrm{C} / \mathrm{min}$. To improve electrical conductivity a graphite paper was used. 3-point bend tests were conducted in rectangular bars $(25 \times 4 \times 4 \mathrm{~mm})$ with a span of $16 \mathrm{~mm}$ at a rate of $0.8 \mathrm{~mm} / \mathrm{min}$. using a TiraTest 2300 tester (Germany).

Batches of samples made by the conventional PM technique were prepared at AGH, Krakow. They were single pressed at $660 \mathrm{MPa}$, according to PN-EN ISO 2740 standard. To minimize friction, zinc stearate was used as a lubricant and was applied on the punches before pressing each sample. Sintering of compacts was carried out in a laboratory tube furnace at $1120^{\circ} \mathrm{C}$ and $1250^{\circ} \mathrm{C}$ for 60 minutes in a mixture of $95 \% \mathrm{~N}_{2}-5 \% \mathrm{H}_{2}$. Heating and cooling rates were $75^{\circ} \mathrm{C} / \mathrm{min}$ and $60^{\circ} \mathrm{C} / \mathrm{min}$, respectively (sinter-hardening). Green and as-sintered densities were calculated by the geometric method. After PM sintering, samples were mechanically tested: tensile test according to 10002-1 standard (the crosshead speed was $1 \mathrm{~mm} / \mathrm{min}$.) using MTS 810 testing machine, 3-point bend test using ZD10-90 machine (following PN-EN 3325 standard on test samples parallel to the pressing direction, with width $5.83 \mathrm{~mm}$, height $5.97 \mathrm{~mm}$ and span of $28.6 \mathrm{~mm}$ ).

For all material variants microhardness was measured on an Innovatest hardness tester (using the Vickers method, 10 measurement points) and metallographic and fractographic observations conducted. Fractography of SPS samples was carried out on VEGA 3 TECAN SEM microscope at the Institute of Material Research, SAS in Kosice.

\section{RESULTS}

\section{Microstructure}

Metallographic investigations of PM steels (Figs. 1a-1f) were carried out on sections etched by $3 \%$ Nital. Microstructure of conventional sintered samples Fe- $1 \% \mathrm{Mn}$ $0.8 \% \mathrm{C}$ consisted mainly of pearlite and ferrite; sometimes bainite. With the increasing 
amount of $\mathrm{Mn}$ to $2 \%$, pearlite, bainite and occasionally martensite were observed in areas surrounding the remnants of ferromanganese particles. In the case of $3 \% \mathrm{Mn}$, the microstructure was considerably heterogeneous consisting of martensitic-bainitic areas with remnants of ferromanganese particles.

\section{$1 \% \mathrm{Mn}-0.8 \% \mathrm{C}(\mathrm{PM}$ steel)}

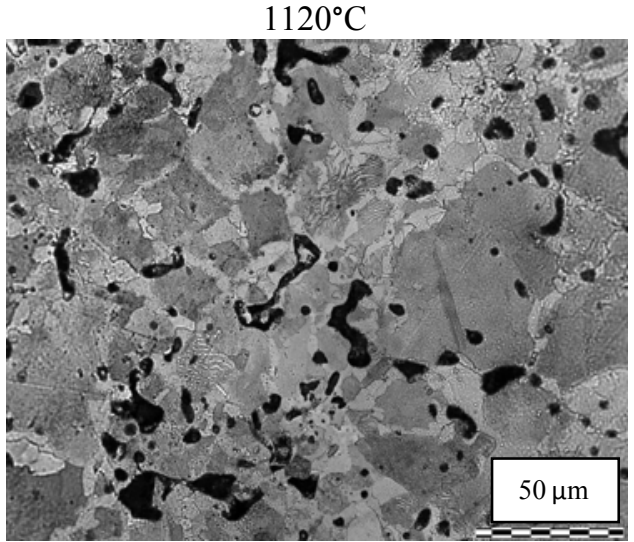

Fig.1a. Microstructure of sample MT1_4 (marker $50 \mu \mathrm{m})$

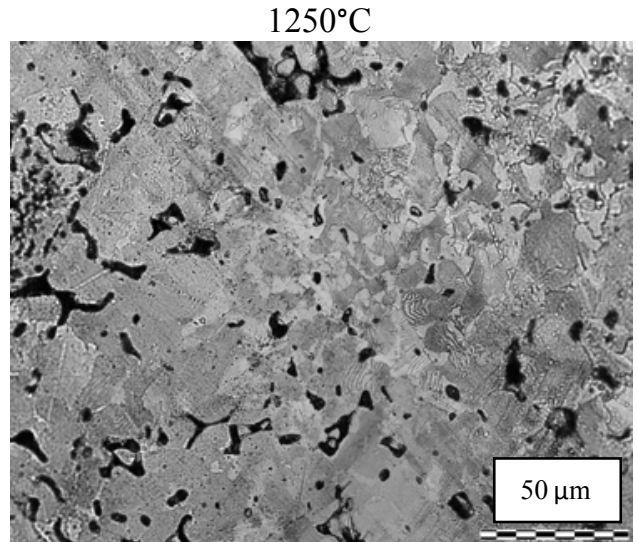

Fig.1b. Microstructure of sample MT2_22 (marker $50 \mu \mathrm{m})$

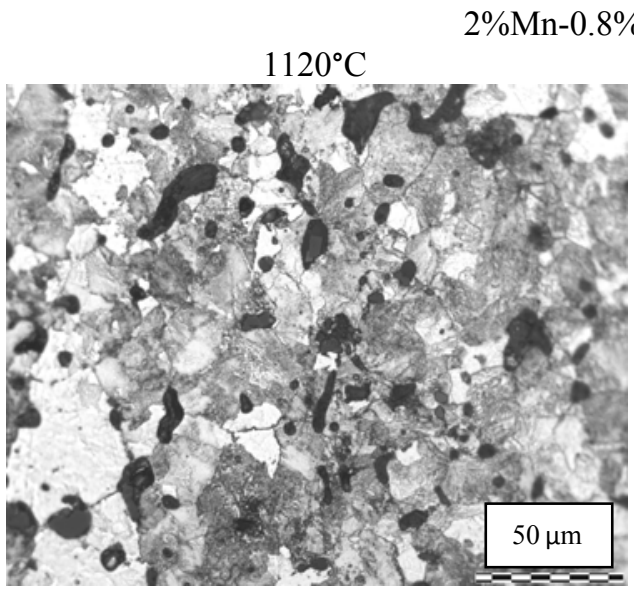

Fig.1c. Microstructure of sample MT3_14 (marker $50 \mu \mathrm{m})$ $1250^{\circ} \mathrm{C}$

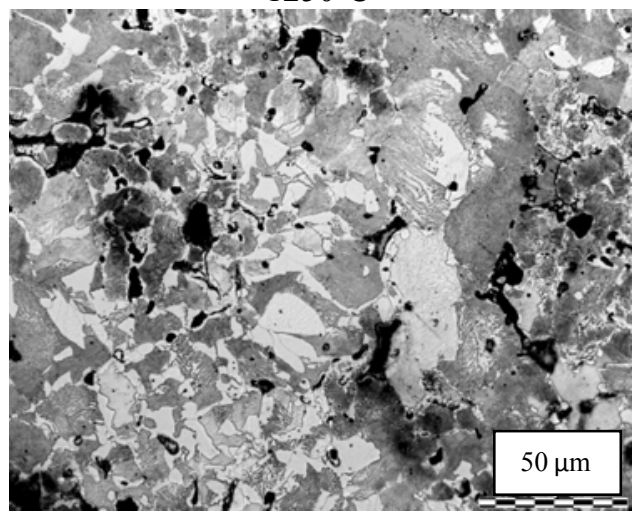

Fig.1d. Microstructure of sample MT4_19 (marker $50 \mu \mathrm{m})$ 


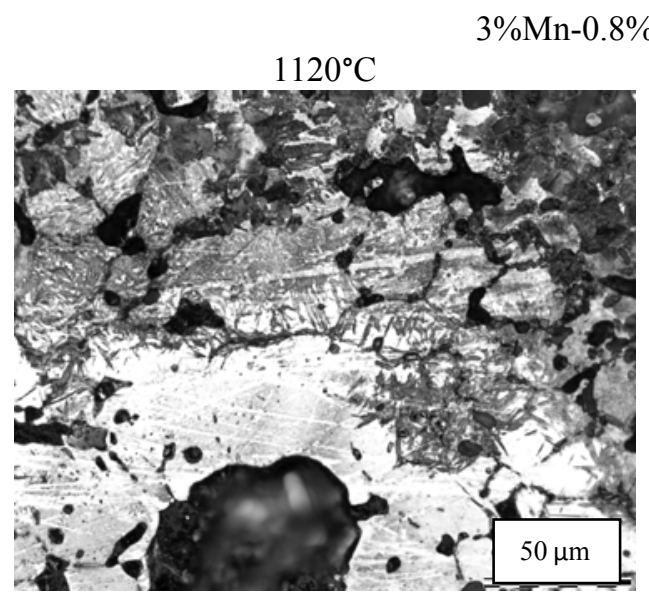

Fig.1e. Microstructure of sample MT5_10 (marker $50 \mu \mathrm{m}$ ).

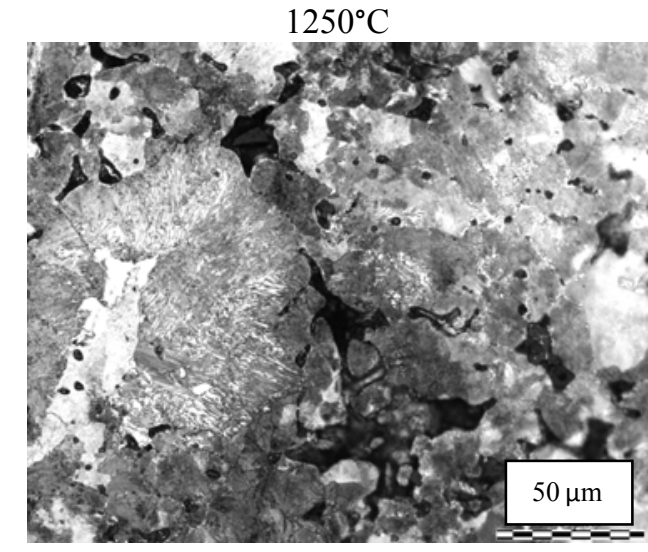

Fig.1f. Microstructure of sample MT6_16 (marker $50 \mu \mathrm{m}$ ).

The microstructure of Fe-1\%Mn-0.8\%C SPS steel (Fig.2a) comprised relatively homogeneously distributed bainitic, coarse and a fine pearlitic structures with some ferritic areas. The SPS steel microstructure with $2 \%$ Mn (Fig.2b) has a similar character but with a slightly higher amount of bainitic areas and a smaller presence of pearlite and ferrite. Some residues of ferromanganese particles can also be identified. The microstructure of SPS steel with 3\% Mn (Fig.3c) is heavily heterogeneous, consisting of fine bainite and large areas of coarse martensitic structures with austenite regions corresponding to locations with high Mn content. A small amount of pores, corresponding to a higher relative density, is typical of SPS steels. The use of graphite paper contributed to carburizing sample surfaces, as shown in Fig.2d.

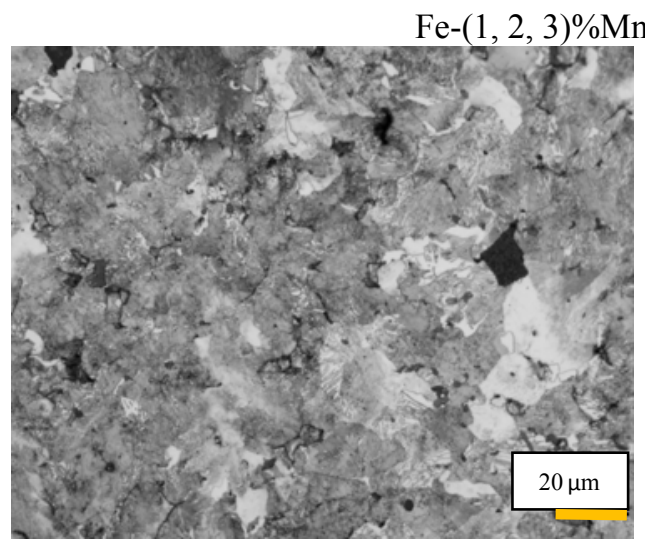

Fig.2a Microstructure of Fe-1\%Mn- $0.8 \% \mathrm{C}$ SPS steel.

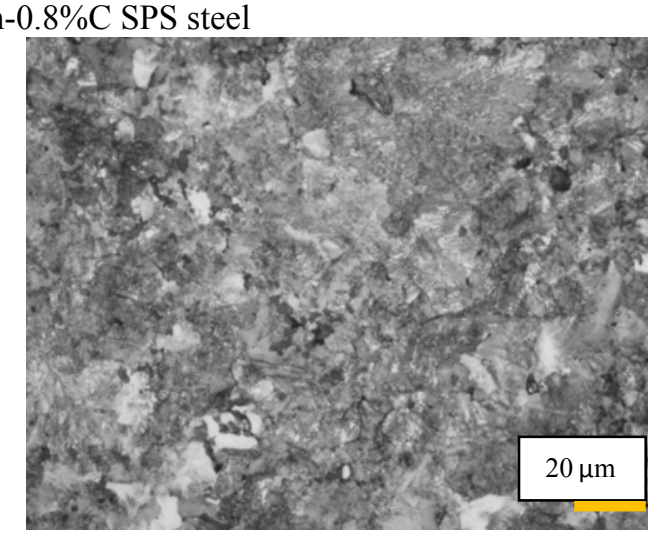

Fig.2b Microstructure of $\mathrm{Fe}-2 \% \mathrm{Mn}-0.8 \% \mathrm{C}$ SPS steel. 


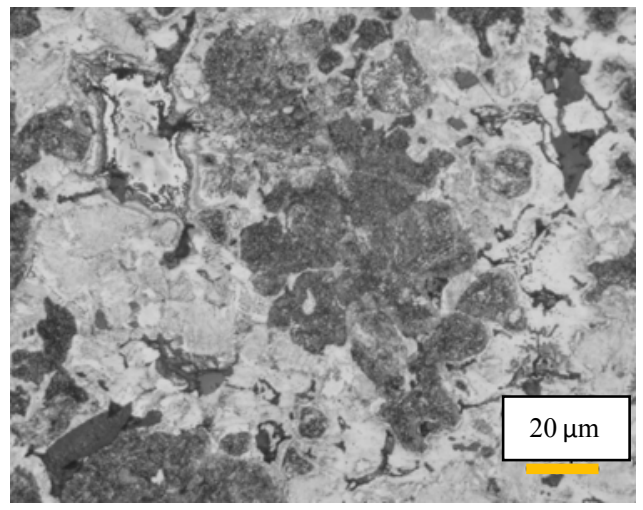

Fig.2c Microstructure of Fe-3\%Mn- $0.8 \% \mathrm{C}$ SPS steel.

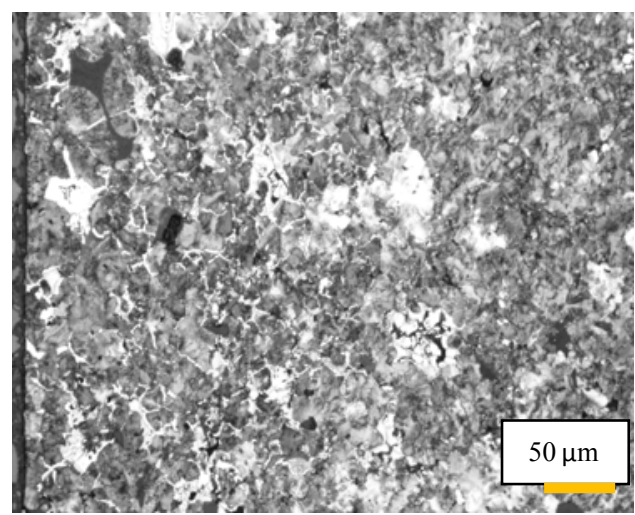

Fig 2d. Carburized surface of SPS sample (marker $50 \mu \mathrm{m})$.

These observations correspond to CCT diagrams [9], taking into account local chemical composition and processing conditions. Increasing the amount of $\mathrm{Mn}$ in these sintered steels widens the range of occurrence of austenite and decreases the amount of bainite on cooling.

\section{Mechanical Properties}

\section{Steels made by the SPS route}

The results of density measurements, bend tests and microhardness for SPS steels are presented in Table 1.

Tab.1. Properties of steels made by the SPS method (batch size: 2).

\begin{tabular}{|c|c|c|c|c|c|}
\hline $\begin{array}{c}\text { No of } \\
\text { batch }\end{array}$ & $\begin{array}{c}\text { Chemical } \\
\text { composition }\end{array}$ & $\begin{array}{c}\text { As-sintered } \\
\text { density }\left[\mathrm{g} / \mathrm{cm}^{3}\right]\end{array}$ & $\begin{array}{c}\text { YS } \\
{[\mathrm{MPa}]}\end{array}$ & $\begin{array}{c}\text { TRS } \\
{[\mathrm{MPa}]}\end{array}$ & HV 0.05 \\
\hline $\mathbf{1 S}$ & Fe-1\%Mn-0.8\%C & $7.36 \pm 0.01$ & $1030 \pm 30$ & $1344 \pm 56$ & $246 \pm 18$ \\
\hline $\mathbf{2 S} *$ & Fe-2\%Mn-0.8\%C & 7.26 & 1220 & 1473 & $316 \pm 28$ \\
\hline $\mathbf{3 S}$ & Fe-3\%Mn-0.8\%C & $7.17 \pm 0.02$ & $920 \pm 80$ & $1234 \pm 18$ & $310 \pm 51$ \\
\hline
\end{tabular}

*one sample in batch

It is to be noted that as-sintered densities are significantly higher than in conventionally sintered steels, Table 2, with a slight decrease with increasing Mn content. As for yield and bend strengths, these are both significantly higher than for conventionally sintered steels, Table 3. Importantly, the $3 \% \mathrm{Mn}$ variant appears to have lower values than $\mathrm{Fe}-1 \% \mathrm{Mn}-0.8 \% \mathrm{C}$, possibly even $\mathrm{Fe}-2 \% \mathrm{Mn}-0.8 \% \mathrm{C}$.

\section{Steels made by the conventional PM route}

The results of physical and mechanical properties of sintered steels made by pressing and sintering are presented in Tables 2 and 3, respectively.

There was no significant swelling or densification, even after sintering at $1250^{\circ} \mathrm{C}$. Increase of all strength parameters, with corresponding decreases in plasticity, Fig. 3, but only to $\sim 3 \%$, with increase of Mn content from 1 to $3 \%$ is as expected [10]. Yield and TRS values are lower than for the denser SPS samples and are higher for $3 \% \overline{\mathrm{Mn}}$ than the $2 \% \mathrm{Mn}$ variant, in contrast to these samples. The highest hardness was for Fe-2\%Mn- $0.8 \% \mathrm{C}$ 
sintered at $1250^{\circ} \mathrm{C}(429 \mathrm{HV} 0.05)$, considerably higher than for the SPS specimen (316 $\mathrm{HV})$. Then in conventionally processed $\mathrm{Fe}-3 \% \mathrm{Mn}-0.8 \% \mathrm{C}$ the hardness decreased, but it was still somewhat higher than in the SPS samples.

Tab.2. Green and sintered densities of pressed and sintered steels (batch size: 15 samples).

\begin{tabular}{|c|c|c|c|c|}
\hline Batch & $\begin{array}{c}\text { Chemical } \\
\text { composition }\end{array}$ & $\begin{array}{c}\text { Sintering } \\
\text { temperature }\end{array}$ & $\begin{array}{c}\text { Green density } \\
{\left[\mathrm{g} / \mathrm{cm}^{3}\right]}\end{array}$ & $\begin{array}{c}\text { Sintered density } \\
{\left[\mathrm{g} / \mathrm{cm}^{3}\right]}\end{array}$ \\
\hline MT1 & \multirow{2}{*}{ Fe-1\%Mn-0.8\%C } & $1120^{\circ} \mathrm{C}$ & $6.67 \pm 0.01$ & $6.65 \pm 0.01$ \\
\cline { 3 - 5 } MT2 & \multirow{2}{*}{ Fe-2\%Mn-0.8\%C } & $1250^{\circ} \mathrm{C}$ & $6.61 \pm 0.008$ & $6.67 \pm 0.01$ \\
\cline { 3 - 5 } MT3 & $1120^{\circ} \mathrm{C}$ & $6.63 \pm 0.01$ & $6.62 \pm 0.01$ \\
\hline MT4 & \multirow{2}{*}{ Fe-3\%Mn-0.8\%C } & $1250^{\circ} \mathrm{C}$ & $6.63 \pm 0.01$ & $6.64 \pm 0.01$ \\
\cline { 1 - 4 } MT5 & $1120^{\circ} \mathrm{C}$ & $6.63 \pm 0.02$ & $6.64 \pm 0.01$ \\
\hline MT6 & & $1250^{\circ} \mathrm{C}$ & $6.59 \pm 0.01$ & $6.59 \pm 0.07$ \\
\hline
\end{tabular}

Tab.3. Mechanical properties of conventionally processed PM steels (batch size: 15 samples).

\begin{tabular}{|c|c|c|c|c|c|c|c|}
\hline Batch & $\begin{array}{c}\text { Chemical } \\
\text { composition } \\
\text { [wt.\%] }\end{array}$ & $\begin{array}{c}\text { Sinter } \\
\text { temp. } \\
{\left[{ }^{\circ} \mathrm{C}\right]}\end{array}$ & $\begin{array}{c}\mathrm{YS} \\
{[\mathrm{MPa}]}\end{array}$ & $\begin{array}{c}\text { UTS } \\
{[\mathrm{MPa}]}\end{array}$ & $\begin{array}{c}\text { TRS } \\
{[\mathrm{MPa}]}\end{array}$ & $\begin{array}{c}\mathrm{A} \\
{[\%]}\end{array}$ & HV 0.05 \\
\hline MT1 & \multirow{2}{*}{$\begin{array}{c}\mathrm{Fe}-1 \% \mathrm{Mn}- \\
0.8 \% \mathrm{C}\end{array}$} & 1120 & $285 \pm 23$ & $511 \pm 22$ & $888 \pm 85$ & $4.36 \pm 0.5$ & $240 \pm 54$ \\
\hline MT2 & & 1250 & $297 \pm 45$ & $587 \pm 32$ & $1070 \pm 95$ & $5.8 \pm 0.54$ & $241 \pm 43$ \\
\hline MT3 & \multirow{2}{*}{$\begin{array}{c}\mathrm{Fe}-2 \% \mathrm{Mn}- \\
0.8 \% \mathrm{C}\end{array}$} & 1120 & $367 \pm 22$ & $611 \pm 22$ & $997 \pm 85$ & $3.73 \pm 0.54$ & $310 \pm 66$ \\
\hline MT4 & & 1250 & $429 \pm 31$ & $713 \pm 53$ & $1200 \pm 88$ & $4.23 \pm 0.6$ & $429 \pm 55$ \\
\hline MT5 & \multirow{2}{*}{$\begin{array}{c}\mathrm{Fe}-3 \% \mathrm{Mn}- \\
0.8 \% \mathrm{C}\end{array}$} & 1120 & $529 \pm 81$ & $626 \pm 29$ & $1112 \pm 108$ & $2.95 \pm 0.3$ & $390 \pm 131$ \\
\hline MT6 & & 1250 & $602 \pm 42$ & $727 \pm 48$ & $1234 \pm 130$ & $3.35 \pm 0.35$ & $343 \pm 87$ \\
\hline
\end{tabular}

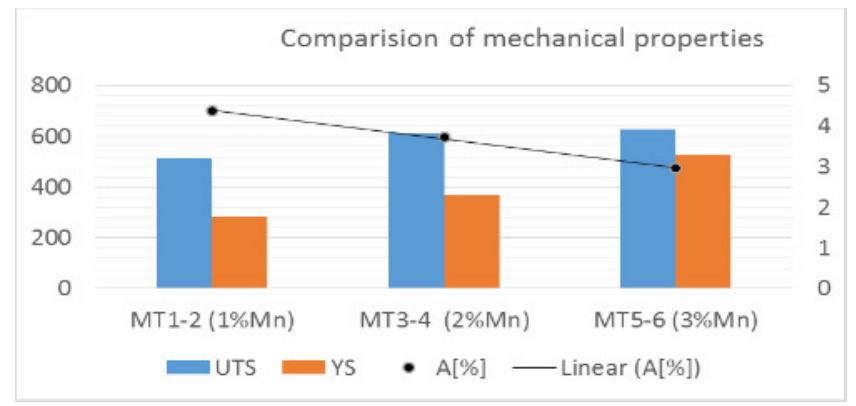

Fig.3. Comparison of mechanical properties (A - linear trend).

\section{Fractography}

In Figures 4a-h and 5a-d some examples of typical characteristics of fracture surfaces of conventionally and spark plasma sintered steels are presented.

The fracture surface of the sample MT1_4 (1\%Mn, $\left.1120^{\circ} \mathrm{C} / \mathrm{SH}\right)$, Fig.4a, contains predominantly fine and coarse shallow dimples, which are typical for interparticles fracture along the interfaces contaminated with oxides. Sporadically areas with elongated dimples initiated by cementite lamellae that correspond to failure in pearlite areas can be seen. As shown in Fig.4b, higher sintering temperature has a positive effect on the development of particle connections, which resulted in the local occurrence of transgranular - transparticle 
fracture. Still, however, shallow dimples initiated by oxide particles prevail. Also, some small areas of local plastic flow were observed. Increasing the Mn content to $2 \%$ (Figs.4c,d) leads to greater oxidation, and this is not eliminated even at the higher sintering temperature. The morphology of this fracture surface is similar to that of $1 \% \mathrm{Mn}$, with the occurrence of a larger amount of oxide particles, which often form large clusters. The higher sintering temperature led to increased size of oxide particles. Significantly heterogeneous microstructure at 3\% Mn with bainitic-martensitic-austenitic regions results in large transgranular cleavage facets combined with some intergranular failure - for steel sintered at the lower temperature, Fig.4e. High sintering temperature is associated with the formation of large austenitic grains, which, together with the oxidic degradation of the grain boundaries, causes a dominant intergranular fracture, Fig.4f.

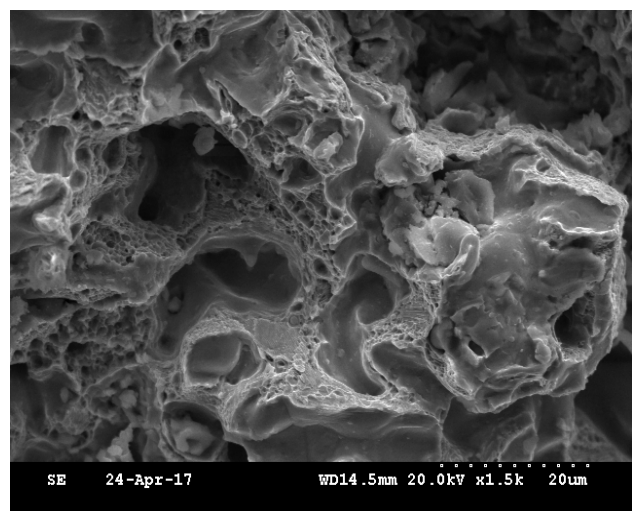

Fig.4a. Fracture surface of MT1_4 sample.

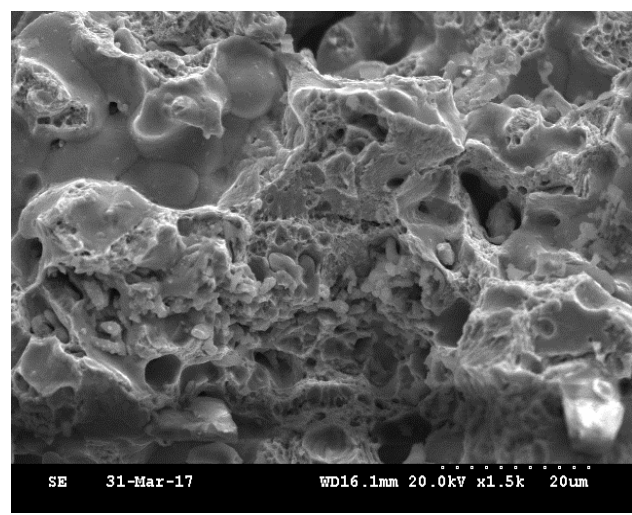

Fig.4c. Fracture surface of MT3_14 sample.

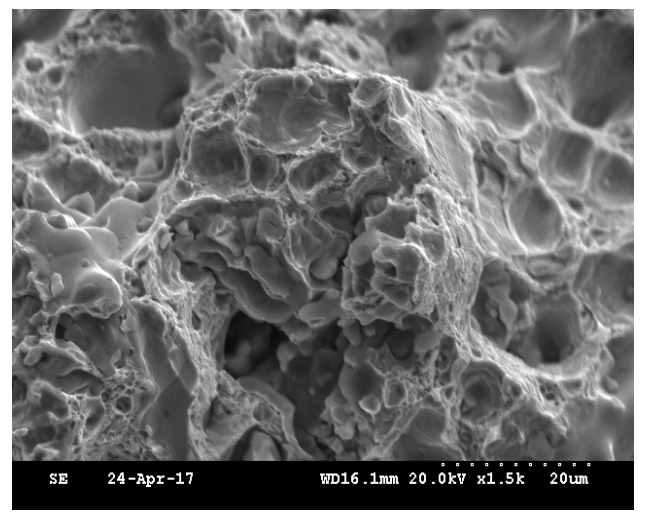

Fig.4b. Fracture surface of MT2_22 sample.

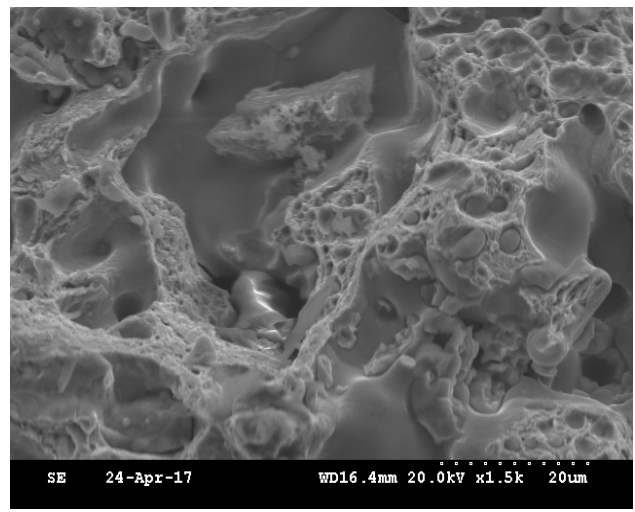

Fig.4d. Fracture surface of MT4_24 sample. 


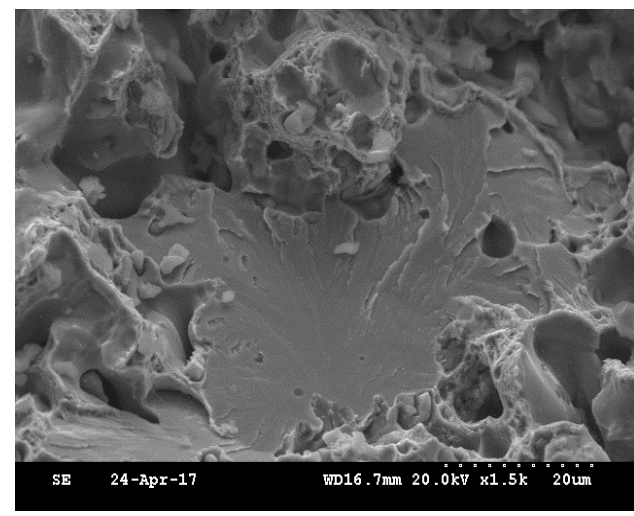

Fig.4e. Fracture surface of MT5_3 sample

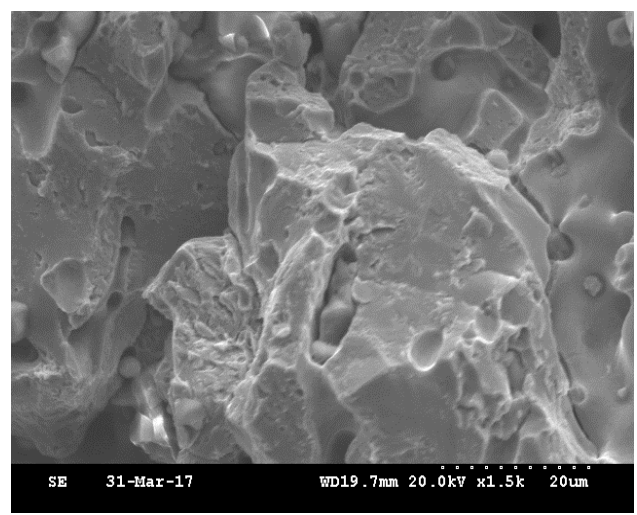

Fig.4f. Fracture surface of MT5_10 sample

Fracture surface of Fe- $1 \% \mathrm{Mn}-0.8 \% \mathrm{C}$ SPS steel, Fig.5a, consists of more-or-less continuous regions of fine shallow dimples initiated by small oxide particles due to oxide contamination of interface areas. In contrast to conventionally sintered steel, relatively good particle connections were developed during SPS. The development of local plastic flow can occasionally be seen. The occurrence of small cleavage facets is only sporadic and the presence of intergranular failure is not typical for this SPS steel. A higher amount of strong structures in Fe-2\%Mn- $0.8 \% \mathrm{C}$ SPS steel results in transgranular fracture of these areas with only little occurrence of intergranular facets, Fig.5b. The presence of local plastic flow areas demonstrates well-developed particle connections. No large clusters of oxide particles have been observed on these fracture surfaces. Higher oxidic contamination of the Fe$3 \% \mathrm{Mn}-0.8 \% \mathrm{C}$ SPS steel microstructure is the cause of a higher portion of intergranular fracture, which alternates with some cleavage or fine shallow dimples, Fig.5c.

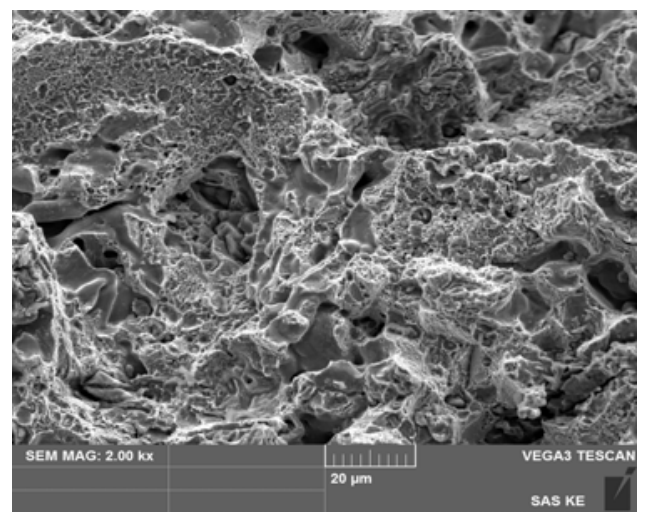

Fig.5a. Fracture surface of Fe-1\%Mn$0.8 \%$ C SPS steel

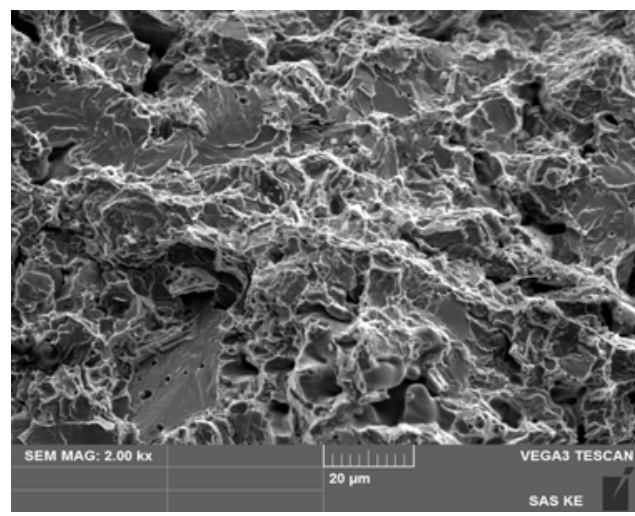

Fig. 5 b. Fracture surface of Fe-2\%Mn$0.8 \%$ C SPS steel 


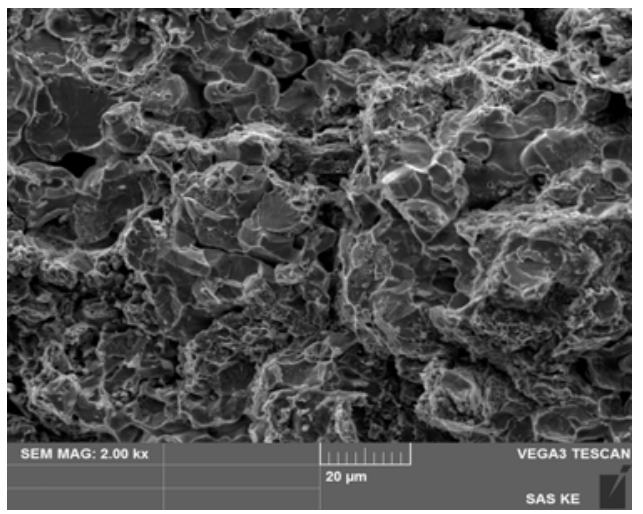

Fig.5c. Fracture surface of Fe-3\%Mn- $0.8 \% \mathrm{C}$ SPS steel

\section{DISCUSSION}

After SPS, the density of samples was higher when compared with the conventionally processed (up to $7.37 \mathrm{~g} / \mathrm{cm}^{3}$ ). The density of SPS samples decreased with increasing amount of manganese. As the Mn content in the steel increases, its density decreases and the SPS temperature is not sufficient for FeMn to diffuse, leaving undissolved particles. Particles of FeMn caused large pores after being filled with oxides and some FeMn remnants.

SPS resulted in bainitic structure for samples with $1 \% \mathrm{Mn}$; for conventially sintered steels it is possible only at $2 \% \mathrm{Mn}$. Application of graphite paper during SPS has contributed to carburizing their surfaces and increased their hardness. Both conventionally and SP sintered steels containing 3\% Mn exhibited highly heterogeneous microstructures with interfaces strongly contaminated with the oxide phase, but much more pronounced in conventionally sintered steels. Clusters of oxide particles associated with a higher number of added FeMn particles in Fe-3\%Mn-0.8\%C SPS steel degraded the quality of the interfaces with further negative consequences on the mechanical properties of this steel, as shown in Table 1.

Higher mechanical properties are connected with the presence of strengthening microstructural constituents, such as bainite and martensite. In the case of increasing Mn content up to $3 \%$, the hardenability of steel increased, which favours the formation of martensite. The development of the microstructure of sintered steel based on a mixture of iron and alloying elemental powders is controlled by chemical and diffusion interactions of the sintered material and the sintering atmosphere. This is a key problem for PM steels alloyed with elements with high affinity for oxygen.

The fracture behaviours of SPS and conventionally sintered steels, corresponding to microstructures, show some differences related to the quality of particle connections, oxide contamination of interfaces, and distribution of individual structural constituents. The fracture surface of $1 \% \mathrm{Mn}$ SPS steel, in contrast to that conventionally sintered, consisted of relatively continuous regions of fine shallow dimples with local plastic flow sites, while the occurrence of intergranular facets is not typical for this SPS steel. This is in good agreement with the relatively favourable strength and plastic properties found for this steel. Increasing the Mn content to $2 \%$, leading to a higher amount of strong structures, resulted in predominantly transgranular cleavage fracture with some small occurrence of intergranular failure. It should be noted that no large clusters of oxide particles were 
observed. The occurrence of a local plastic flow confirmed the presence of well-developed particle connections, which corresponds with higher mechanical properties, when compared to $1 \% \mathrm{Mn}$ SPS steel. In contrast, the occurrence of a higher oxide contamination of $3 \% \mathrm{Mn}$ SPS steel, reflected in presence of intergranular facets combined with some cleavage or shallow dimples, seems to be in good agreement with the slightly lower strength properties of this steel compared to those for 1 and $2 \%$ Mn SPS steels.

The fracture surface of conventionally sintered $1 \% \mathrm{Mn}$ steel, consisting of fine and coarse shallow dimples, is the consequence of strong oxidation of weak particle connections and high residual porosity. Higher sintering temperature led to local occurrence of transgranular fracture with the prevalence of shallow dimples, however, initiated by oxide particles. Increasing the Mn content to $2 \%$ resulted in higher oxidation for both sintering temperatures. Failure seems to be similar, however, to that of the $1 \% \mathrm{Mn}$, but with the occurrence of oxide clusters. Higher sintering temperature promoted an increase in oxide particle size. Despite the relatively large amount of oxide particles, the oxidation of grain boundaries was less pronounced, as evidenced by a smaller presence of intergranular facets, which was reflected in some plasticity and acceptable elongation values for both 1 and $2 \% \mathrm{Mn}$ steels. Increasing the Mn content to 3\% and lowering the sintering temperature resulted in significantly heterogeneous microstructure, resulting in failure with large cleavage facets in bainitic-martensitic-austenitic regions. As opposed to 3\% Mn SPS steels, the microstructure of conventional steel sintered at $1250^{\circ} \mathrm{C}$ contained large austenitic grains which, together with a strong oxidation of grain boundaries, resulted in intergranular fracture and thus to embrittlement of $3 \% \mathrm{Mn}$ conventionally sintered steel. This phenomenon did not occur in the case of SP sintered steel. The morphology of fracture surfaces indicates that SPS, after eliminating the oxide contamination of the interfaces, could lead to a significant increase in mechanical properties when compared to conventional sintering.

Results of this work suggest that SPS processing of Mn alloyed steels could somehow eliminate negative oxidation processes. It can be assumed that choosing the optimal Mn content that provides a preferred microstructure and high relative density can provide a good combination of mechanical properties. From the point of view of the surface hardness of the SPS parts thus prepared, the presence of the carbide phase in the surface areas could also be advantageous. On the other hand, their impact on the initiation of the cracks should be considered. Several of these questions should be the subject of further discussion, especially if the optimal Mn content is from $2-2.5 \%$.

\section{CONCLUSIONS}

1. For both conventionally sintered and SPS steels, the most favorable combination of mechanical properties was achieved for chemical composition Fe-2\%Mn- $0.8 \% \mathrm{C}$, though yield, tensile and bend strengths of conventionally processed $\mathrm{Fe}-2 \% \mathrm{Mn}-0.8 \% \mathrm{C}$ were higher.

2. Samples after SPS were characterized by higher density, yield and bend strength, when compared to conventional PM steels.

3. These properties for SPS steels were up to $7.37 \mathrm{~g} / \mathrm{cm}^{3}, 1220$ and $1473 \mathrm{MPa}$, respectively.

4. SPS resulted in bainitic structure in steels containing $1 \% \mathrm{Mn}$.

5. These preliminary results indicate that further research on SPS of Mn steels is warranted. 


\section{Acknowledgements}

The financial support of the Ministry of Science and Higher Education under AGH University of Science and Technology contract no 11.11.110.299. The authors would like to thank Prof. A. S. Wronski for his content-related comments and editing this text.

\section{REFERENCES}

[1] Hryha, E., Nyborg, L., Dudrova, E., Bengtsson, S. In: Proc. Euro PM2009 - Sintered Steels 1 - Composition. International powder metallurgy congress et exhibition. Copenhagen, 12.-14.10.2009. Vol. 1. Shrewsbury: EPMA, 2009, p. 17

[2] Taylor, GF.: US Patent No. 1,896,854, 1933

[3] Taylor, GF.: US Patent No. 1,896,853, 1933

[4] Crèmer, GD.: US Patent No. 2,355,954, 1944

[5] Lenel, VF.: JOM - the Journal of The Minerals, Metals \& Materials Society (TMS), Trans. AIME, vol. 7, 1955, no. 1, p. 158

[6] Song, X., Liu, X., Zhang, J.: Journal of American Ceramic Society, vol. 89, 2006, no. 2, p. 494

[7] Zhaohui, Z., Fuchi, W., Lin, W.: Materials Letters, vol. 62, 2008, no. 24, p. 3987

[8] Hebda, M.: Czasopismo Techniczne, z. 11, Mechanika, z. 6-M, 2012, no. 11, p. 47

[9] Cias, A.: Development and Properties of Fe-Mn-(Mo)-(Cr)-C Sintered Structural Steels. AGH - Uczelniane Wydawnictwa Naukowo-Dydaktyczne, 2004

[10] Dudrova, E., Kabatova, M. In: Fractography - Principles and Application, Workshop. March 23-25, 2015, Košice, Slovakia 